\title{
Intention to Use Intelligent Conversational Agents in e- Commerce among Malaysian SMEs: An Integrated Conceptual Framework Based on Tri-theories including Unified Theory of Acceptance, Use of Technology (UTAUT), and T-O-E
}

Abayomi Oluwaseyi lkumoro, Mohammed Saeed Jawad

To Link this Article: http://dx.doi.org/10.6007/IJARBSS/v9-i11/6544

DOI: $10.6007 /$ IJARBSS/v9-i11/6544

Received: 15 October 2019, Revised: 29 October 2019, Accepted: 04 November 2019

Published Online: 19 November 2019

In-Text Citation: (Ikumoro \& Jawad, 2019)

To Cite this Article: Ikumoro, A. O., Jawad, M. S. (2019). Intention to Use Intelligent Conversational Agents in eCommerce among Malaysian SMEs: An Integrated Conceptual Framework Based on Tri-theories including Unified Theory of Acceptance, Use of Technology (UTAUT), and T-O-E. International Journal of Academic Research in Business and Social Sciences, 9(11), 205-235.

\section{Copyright: (c) 2019 The Author(s)}

Published by Human Resource Management Academic Research Society (www.hrmars.com)

This article is published under the Creative Commons Attribution (CC BY 4.0) license. Anyone may reproduce, distribute, translate and create derivative works of this article (for both commercial and non-commercial purposes), subject to full attribution to the original publication and authors. The full terms of this license may be seen at: http://creativecommons.org/licences/by/4.0/legalcode

Vol. 9, No. 11, 2019, Pg. 205 - 235

Full Terms \& Conditions of access and use can be found at http://hrmars.com/index.php/pages/detail/publication-ethics 


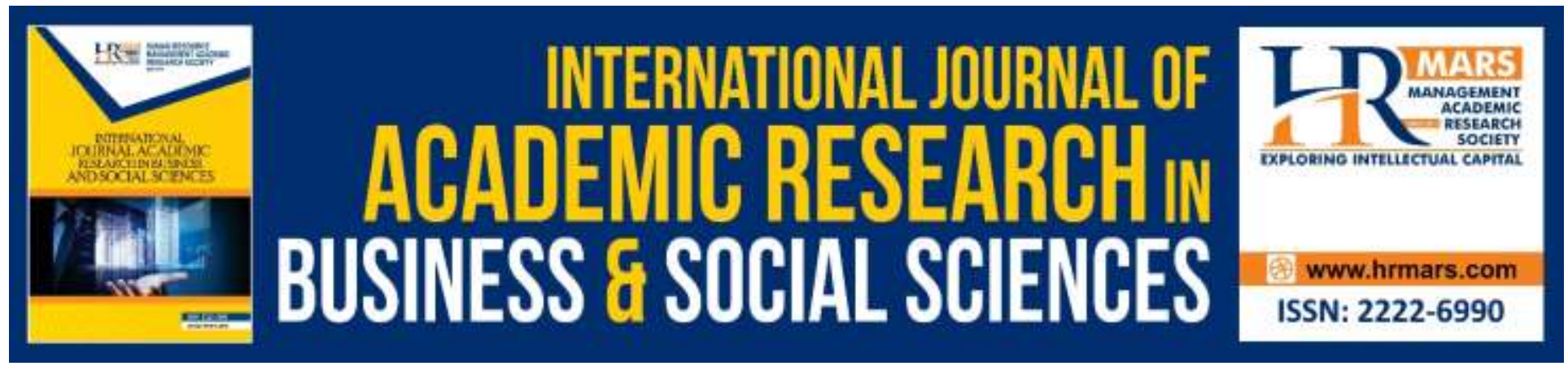

\title{
Intention to Use Intelligent Conversational Agents in e-Commerce among Malaysian SMEs: An Integrated Conceptual Framework Based on Tri- Theories including Unified Theory of Acceptance, Use of Technology (UTAUT), and T-O-E
}

\author{
Abayomi Oluwaseyi Ikumoro, Mohammed Saeed Jawad \\ Post Graduate Centre (PGC), Lim Kok Wing University of Creative Technology, Inovasi 1, 1, Jalan \\ Teknokrat 1/1, Cyberjaya, 63000 Cyberjaya, Selangor, Malaysia. \\ Email addresses: abayomiikus@gmail.com, saeed.jawad@limkokwing.edu.my
}

\begin{abstract}
Despite Industrial Revolution 4.0-related awareness, assessment, support, and training from the government and relevant agencies, the adoption rate of digital technologies usage is relatively slow. Such technologies include intelligence conversational agents/chatbots-artificial intelligence (AI)/virtual assistant, which are used by Malaysian small and medium enterprises (SMEs) in supporting their business operation in areas such as sales and marketing, conversational commerce, customer service support, data analytics, and organisation sustainable development. Therefore, this particular work explored the extrapolative elements for explaining the Malaysian SMEs intention to utilize intelligence conversational agents for an e-commerce system. The study was born out of the researcher's enthusiasm to proffer measures that could motivate SMEs, which functioned as the country's economic backbone, towards becoming accustomed to the rapid technological developments and evolving innovations advanced by digital technologies. In this research, the constructs of the unified theory of technology acceptance and use of technology (UTUAT) model were reviewed and synergised into the technology-organizationenvironment (TOE) framework, with perceived cost and perceived technology security to propose an improved conceptual framework. The integrated conceptual framework proposed established 11 factors (i.e. employees technology know-how, performance expectancy, perceived relative advantage, perceived technology security, chief executive officer (CEO) and manager characteristics, perceived adoption cost, facilitating condition, social influence, hedonistic drives, and normative and mimetic pressures) in promoting and aiding future
\end{abstract}


INTERNATIONAL JOURNAL OF ACADEMIC RESEARCH IN BUSINESS AND SOCIAL SCIENCES

Vol. 9, No. 11, November, 2019, E-ISSN: 2222-6990 @ 2019 HRMARS

research, as well as serving as guidance for delineating and predicting the adoption of intelligence conversational agent among SMEs in Malaysia.

Keywords: Intention to Use, UTAUT, T-O-E, E-Commerce, SME, Intelligence Conversational Agents

\section{Introduction}

Industry 4.0 technologies are transforming every facet of business in today's globally competitive market. Nowadays, e-commerce organizations are revolutionizing the manner in which they conduct their businesses for sustainability in the business environment. This is done by providing solutions to engage consumers, improve customer lifecycle, customize purchasing experiences, empower employees, offer consumer-optimized production, serve consumer-added product benefits, and facilitate the growth of digital businesses. Such information is pertinent to small and medium scale enterprises (SMEs) as technological innovation usage will spur their competition with large organizations. Based on the organisation for economic co-operation and development (OECD) reports, SMEs have been reported to account for over $95 \%$ of all firms. In this context, SMEs refer to firms that employ up to 249 people; specifically, one to nine people for micro-enterprises, 10 to 49 people for small enterprises, and 50 to 249 people for medium enterprises. In the perspective of employment, SMEs provide 60 to $70 \%$ of total employment, thus generating a large share of new jobs (OECD 2019). They account for $22 \%$ of the population in developing economies, whereas $99 \%$ of North American and European businesses are SMEs (Awa et al. 2012). Similarly, Australian SMEs provide $70 \%$ of employment, as well as one-third of the country's Gross Domestic Product (GDP) (Scupola, 2009).

In the context of the Malaysian economy, $98.5 \%$ of businesses established locally consists of SMEs and cut across all sizes and sectors, namely agriculture, mining and quarrying, manufacturing, construction, and service sectors (Department of Statistics Malaysia (DOSM) 2018). They have contributed $37.1 \%$ to the GDP, $17.3 \%$ for exports, and accounts for $66 \%$ of employment; these numbers are expected to rise in the coming years. Notwithstanding this expectation, scholars have highlighted low or slow technological adoption rates among these SMEs in spite of various governmental efforts in terms of training, financial support, and awareness (Alam et al. 2011; Tan et al. 2009; SME Corp. Malaysia 2018; Jones et al. 2013; Abdullah et al. 2013; Kurnia et al. 2015; Abdullah et al. 2017; Ismail et al. 2018; Idris 2019; Hamid et al. 2019). Moreover, the existing technology adoption models are yet to provide sufficient insights on the significant factor(s) capable of impacting towards a successful technology adoption within the SMEs.

By tailoring the SMEs to the megatrend of Industrial Revolution 4.0 (IR 4.0) may ultimately result in a digitalized way of life, whereby automation and the Internet of Things (IoT) are extensively implemented in practically all facets of the day-to-day routine, business, society, individuals, and economies. However, an urgent need is apparent for enhanced facilitation among Malaysian SMEs in achieving its master plan (2012-2020), namely by tailoring blueprints and approaches with such megatrends. It inevitably necessitates these entities to supply 'addedvalue' services and products, or quality and novel products and services (Abdullah et al. 2017; 
Ismail et al. 2018. According to Idris (2019), IR 4.0 makes use of software application as a channel for automating business activities towards stimulating manufacturing productivity. This is undertaken by enhancing the connectivity between humans and machines towards synchronizing the physical assets and digital world together for industrial efficiency. Furthermore, IR 4.0 has displayed immense potential in modifying the manufacturing SMEs in a wide-ranging perspective, specifically by enhancing the productivity; efficient and cost; improving the organizational, managerial, and production capabilities; allocating improved quality and monitoring; and establishing the innovators and producers of IR 4.0 technologies (Ministry of International Trade and Industry (MITI) 2018). Due to this notion, SMEs that are quick to grab such chance due to the Megatrends may find themselves positioned for significant gains (Malaysian SME Corp. 2017). A report has listed out several benefits for industries to shift towards IR 4.0, such as enhanced flexibility, better productivity, higher efficiency and quality, less time-to-market, in-depth research development and demonstration (R\&D\&D) activities, and the possibility for novel skills and talent establishment worldwide. It is of utmost importance for SMEs to restraint themselves from the traditional brick-and-mortar ways of doing business; they should instead embrace digital transformation and adopt technology innovation to maintain their relevance and success in today's globally competitive market.

The survey undertaken by the Federation of Malaysian Manufacturers (FMM) and Malaysian Institute of Economic Research in 2016 showed that merely 12\% of their participants were fully aware of the IR 4.0 wave (The Edge Markets 2017). Other researchers (Abdullah et al. 2017; Idris 2019) have further noted that the Malaysian government needs to spur more awareness of the wave and engage the stakeholders as a large percentage of SMEs are less comprehensive regarding its importance and benefits. On the contrary, the government has currently implemented 40 and more e-commerce-based strategies and approaches, such as GoGlobal Malaysia (\#MYGoGlobal) that helps local SMEs to investigate new markets via digitalisation and incorporation of the right comprehension and instruments. Furthermore, other examples include the establishment of the world's pioneering Digital Free Trade Zone (DFTZ), a collaborative effort between Malaysia and globally-acknowledged internet and e-commerce organizations, Catcha Group and Alibaba Group, achievable through its ministries and agencies such as Ministry of International Trade and Industry (MITI), Ministry of Finance (MOF), Malaysia Digital Economy Corporation (MDEC), Bank Negara Malaysia (BNM), Malaysian Administrative Modernization and Management Planning Unit (MAMPU) others in order to boost e-commerce growth (Hashim \& Jumabhoy, 2017). Besides, other initiatives include Go e-commerce, which is a public-private collaboration between Google and selected industry partners. This serves to empower Malaysian SMEs in developing their business capacities, engaging with appropriate digital ecosystem partners, highlighting international export activities, and becoming globally competitive entities (Jayakrishnan et al. 2018).

In the foregoing, SMEs that seizes the opportunities arising from the Megatrends stand to gain significantly (SME Corp. Malaysia 2017). The report listed several benefits for industries moving onto IR 4.0, such as, increase in flexibility, increase in productivity, increase in efficiency, quality and reduced time to market, and the potential of developing new skills and talent globally. 
Therefore, SMEs should not be confined to the traditional brick and mortal ways of doing business but rather embrace digital transformation, and the advantageous benefits of adopting innovative technology in order remain relevant and successful in today's globally competitive market.

Therefore, the current work aimed to delineate a review of existing literature on Al-based applications used by e-commerce firms globally in the context of technology acceptance in Malaysian SMEs. Currently, the most popular Al-based application in businesses is Intelligence Conversational Agents and Chatbots-Al, Virtual Assistants, Smart Logistics, and Recommendation Engines (Sennaar, 2019). However, the emphasis was placed upon exploring the application and technology acceptance of Intelligence Conversational Agents and Chatbots-Al in Malaysian SMEs as the software application may potentially shift the approach in which SMEs digitally engage and communicate with their customers (Eeuwen, 2017) so as to provide digital insights for business sustainability. The end of this work included an integral framework conceptualized per the Unified Theory of Acceptance and Use of Technology (UTAUT) (Venkatesh et al. 2003) and Technology-Organization-Environment (T-O-E) (Tornatzky \& Fleischer, 1990) constructs.

\section{Overview of Small and Medium Enterprise (SME)}

SMEs are oftentimes categorized according to the number of employed individuals, annual revenue, and/or asset values. United State (US) Small Business Administration (SBA) defines small firms depending on the type of industry they belong to. Two criteria are utilized to define SMEs, namely as a firm with sales turnover not more than RM50 million or full-time staff not more than 200 for the manufacturing sector; for the services and other sectors, not more than 75 full-time staff roster. However, this work adopted the definition via size or number of staff to define SMEs: they are businesses staffed with not more than 10 staffs for micro-enterprises, 10 to 50 staffs for small enterprises, and 50 to 250 staffs as medium-sized enterprises. This parallels the definitions of prior studies for Southeast Asian countries (Kurnia et al. 2015; Ismail et al. 2018, which define SMEs as an entity with less than 50 staffs or yearly sales turnover, not more than RM5 million.

Several scholarly articles have shown that technological adoption increases the success rate of its adopters compared to non-adopter SMEs (Abdullah et al. 2013; Awa et al. 2015; Ameyaw \& Modzi 2016; Kurnia et al. 2015; Abu et al. 2015; Lahiri et al. 2018 Hamid et al. 2019). In contrast, Abu et al. (2015) have claimed that Malaysian SMEs utilize very restricted scopes of technologies and are thus unable to compete in the global market. Moreover, the existing models on technology adoption within Malaysian SMEs have failed to yield a satisfactory understanding regarding the factors capable of influencing a successful acceptance, despite the government's continuous support in promoting technology adoption through its agencies (Abdullah et al. 2013). Other studies have further found various barriers to the technology innovation adoption in Malaysian SMEs, such as perceived security and privacy; employee education level of skill in information and communications technology (ICT) and cost of ICT infrastructure (Saleh \& Burgess 2009; Jones et al. 2013; Ismail et al. 2018); and the absence or insufficient finance resources, ecommerce knowledge, and important regulations and standards for e-commerce (Ameyaw \& Modzi 2016; Hamid et al. 2019). Other factors also include perceived benefit, lack of sufficient 
skill and knowledge, lack of awareness of e-commerce technologies with little or no exposure to the industrial standards, and minimal awareness of e-commerce capabilities compared to larger trading partners (Kurnia et al. 2015).

Similarly, some elements are likely to significantly influence e-commerce technology adoption, which are CEO academic qualification, passion, commitment, technology know-how, leadership style, technological awareness, and their willingness to learn, skillful and competent staffs, organizational culture, and customer orientation based on market trends and government (Abdullah et al. 2013; Ismail et al. 2018). Additionally, organizational readiness and external pressure from business partners (Shaharudin et al. 2012; Ahmad et al. 2015) and relative advantage (Ramayah et al. 2016) are some of the added advantages.

\section{Digital Transformation of Small and Medium Enterprise (SME) based on IR 4.0}

The Malaysian economy fundamentally consists of SMEs, thus rendering their consistent success as pertinent for the country's wellbeing. As of 2016, SMEs make up for a whopping $98.5 \%$ of all businesses established in Malaysia. Furthermore, the statistics from SME Corporation indicate that they comprise of approximately one million businesses (Hashim \& Jumabhoy, 2017). Therefore, these 907,065 business proprietors are facing direct challenges: how to build the business and ensure it is sustainable? Generally, entrepreneur-based technology companies, cafés, food delivery, shopping, and more make up the main bulk of Malaysian SMEs, which have increased in numbers over the past few years. They are generally services-oriented (89.2\%), but may also come from the manufacturing, distribution, retail, construction, and agriculture sectors. They have gone through more than 20 years of a time period to succeed, which is not based on the emergence of internet connectivity. Instead, it is a result of their own money investments and struggles of getting bank loans, whereby such experience has shaped the perspectives of which a business may be established and managed.

However, as digitalization increases worldwide, it is extremely critical for Malaysian SMEs to spontaneously adopt digital technologies so as to spur economic growth (Malaysian SME Corporation 2017). Digitalization is defined as the business process transformation, which includes customer management, transaction, services, and feedback in a completely digital environment. Nonetheless, research surveys have shown that Malaysian SMEs are still struggling with digital developments, which is due to barriers in infrastructure, regulatory and managerial limitations, and inadequate access to finance and digital skills. Although these entities are highly computerized, they lack the willful force to digitalize their businesses; this requires a change of mindset and the development of a digital workforce for the industry ecosystem to work upon (Malaysian SME Corporation 2017).

Generally, digital transformation is powered by technological developments and innovations. However, technology has drastically changed the medium in which the business world communicates in a digital climate. The old means of collecting data for client information preservation to enhance SMEs' productivity, growth, market reach, sales, cost efficiency, and competitive advantage produce minimum or no result for them, which are then transformed significantly with the advent of digital technologies. Digital transformation has reshaped the way 
SMEs and large organisation conduct their business operations and manage their relationship with customers (Markelova, 2017). According to Taiminen and Karjaluoto (2015), SMEs have yet to utilize the full potential offered by new digital tools. Therefore, they are not extracting any benefit offered by opportunities such as tools provided, which is mostly due to the lack of technological knowledge. This further indicates that many SMEs are really not understanding of the fundamental changes in the nature of communication, which is positioned by digitization. Regardless, technologies such as automated messaging and/or communication systems, innovative advancement with $\mathrm{Al}$, and big data analytics are some of the applications that facilitate the transformation of existing e-commerce ecosystems (Gentsch, 2019).

Moreover, up-and-coming business and technology tendencies may help in remolding the corporations towards a sustainable future (Kaur \& Sharma, 2017). These technologies offer better access to new markets, support new product development, enable on-demand service deliveries, and provide a platform for innovative business models. This model presents the novel capability to access, collect, and store data that is capable of enhancing the future organizational progression, if the data are gathered effectively. By doing so, SMEs are able to evaluate the development of their product growth, performance, and competitiveness. Technological advancement has brought about new innovation into various industries spanning from banking and finances to customer services; it allows for ensuring customer satisfaction in the retail and e-commerce sectors, which includes personalized recommendations (Ufford, 2017). Similarly, smart manufacturing enables remote diagnosis in healthcare and social assistance (Laumer et al. 2019) to accommodation and food firm are taking place (Walker 2019). In contrast, SME Corp. Malaysia (2018) has revealed that Malaysian SMEs understand the importance of technology adoption in business, as well as its impact on productivity and efficiency (Malaysian SME Corporation, 2017). The study has further shown that the manner in which high usage of technological innovation among SMEs increases their productivity to $60 \%$ compare to $27 \%$ and $26 \%$, respectively, for limited, middle, or low users. However, only $35 \%$ among 2,033 SMEs interviewed has adopted loT in their businesses, which is mainly used for security, surveillance, or fleet management alone.

"Industry 4.0" commonly refers to the fourth industrial revolution, which allows the connection between machines, people, and physical assets into an integrated digital ecosystem. It allows seamless generation, analysis, and communication for data; sometimes, it takes action based on available data without the need for human intervention (Caletka, 2016). The connection is powered by rapid technological developments and evolving innovations known as digital transformation. However, these technologies allow robust perspectives via big data analytics, thereby bringing new dimensions to the industrial landscape and yielding a drastic increment of industrial productivity (MITI, 2018). 


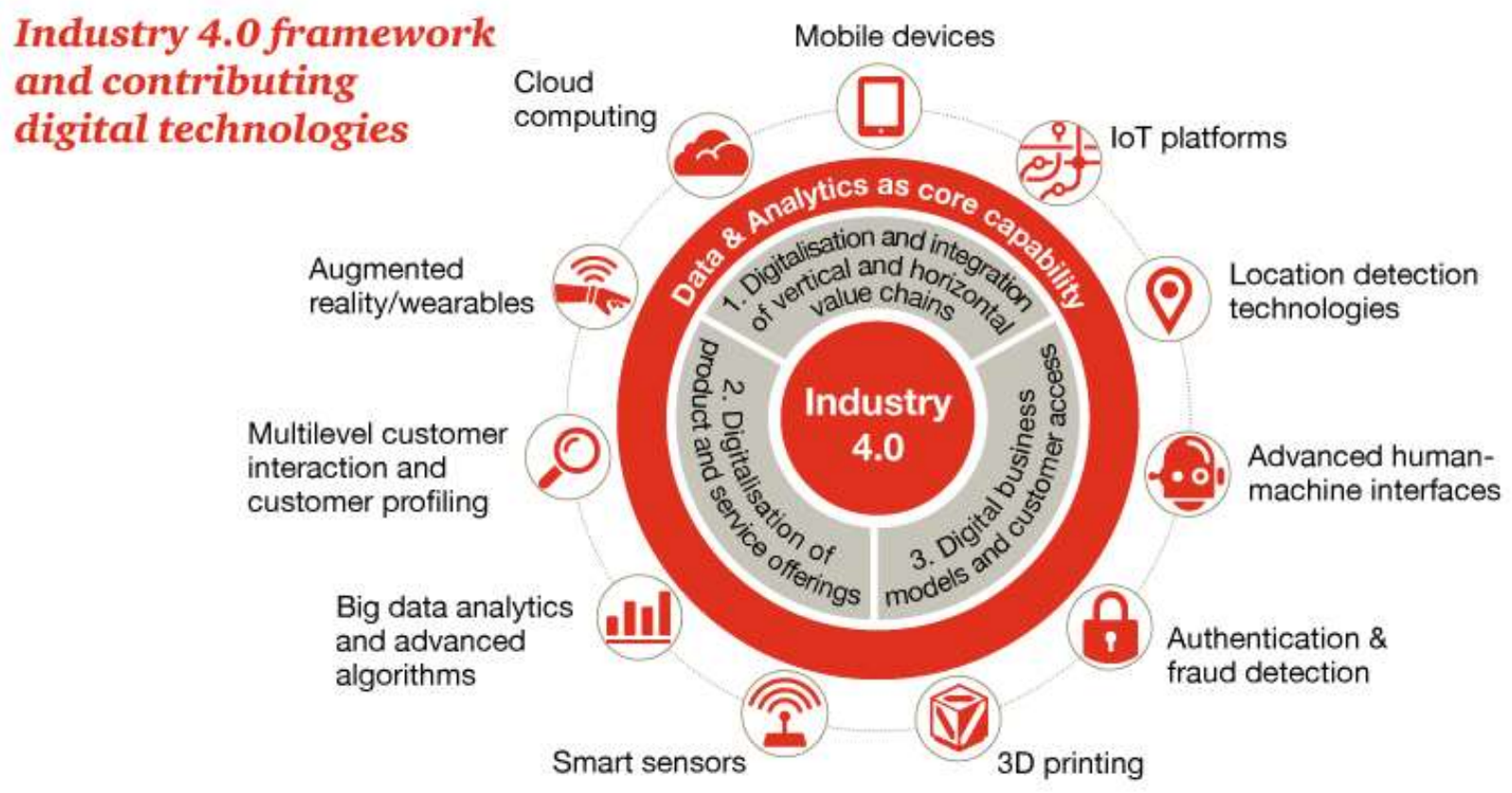

Source: Industry 4.0: Bulding the digital enterprise, 2016 Global Industry 4.0 Survey. PWC, Engineering \& Construction, 2016

Figure 1: Industrial 4.0 Framework and its encapsulating digital technologies

Advances in Al, which encompasses the advanced human-machine interfaces and big data with the use of techniques such as machine learning and deep learning, have taken advantage of the vast amount of data. In combination with the affordable processing power, they dramatically improve the quality of understanding and decision. They facilitate the rapid growth of intelligence conversational agent/Chatbots-AI/Virtual Assistant, which is capable of automating communication while perceived as human interaction still. The novel paradigm shift in communication puts forth various tendencies, such as customer advice and purchase via communication (Conversation Commerce); digital personal assistants who undertake purchasing, bookings, and planning tasks for consumer (Personal Butlers); algorithms ad bots integration in every step of a marketing process (Algorithm Marketing); and the implementation of messaging platforms in combination with Chatbots-Al in internal company processes (Conversational Office) (Gentsch, 2019). The first Chatbot in history is named ELIZA, previously developed by Joseph Weizenbaum in the 1970s (Reshmi \& Balakrishnan, 2018). Meanwhile, Osman (2019) has predicted that by $2020,80 \%$ of businesses will be using chatbots due to its ability to resolve problems with minimal human resources and reduced organizational costs. As 2021 looms, an estimated 1.8 billion people will find themselves benefiting from voice search technology, which has extended beyond personal use to official work purposes. Forecasts have placed the expected growth of such virtual digital assistant from 2017 to 2021 to reach from 3 billion dollars to 15.79 dollars (Ali 2018). Regardless, challenges and obstacles are also emerging with regards to security and privacy, and transactions and consumer data confidentiality.

The primary goal of these technologies is to facilitate sales as powered by the rise in Al. In the digital environment, reports from Malaysian SME Corporation (2017) have shown that 
most Malaysian SMEs want to develop new products and services, increase online marketing, develop employee skill technology capabilities (particularly the manufacturing and service sectors), and develop a new business strategy so as to conform with digital transformation. To achieve this, they need to understand their target audience, and consequently adopt digital technologies that will automate the whole process of data warehousing for analytical purposes. This allows them to understand market trends and consumer behavior, improve business strategies, and highlight new opportunities in the global market, thus rendering marketing strategy to be of importance in every sector.

As the central element for all business activities, marketing is further advanced by the role of $\mathrm{Al} /$ augmented reality/machine learning, video marketing, intelligence conversational agents/chatbots, $\mathrm{Al}$ / virtual assistant, and data transparency and personalization among digital marketing tools, which are rated higher and expected to increase (Kotane et al. 2019). Without marketing, the organisation cannot sell; in the absence of sales, no revenue is obtained; and if revenue is lacking, proprietors cannot operate businesses. This contributes to the rising presence of a novel type of business ecosystem, fresh approaches to scale businesses, and varying classes of marketing and finance technologies serving as the "universal connector". Through this, the business can be undertaken with anonymity even at a huge scale on the business platform via cloud infrastructure and talent externalization (Kaur \& Sharma 2018). The awareness regarding such tendencies facilitates these SMEs to make influential and unconventional strategies in approaching corporate sustainability. Therefore, herein lies the motivation for this research: to examine intelligence conversational agent/Chatbots - Al application and acceptance in Malaysian SMEs.

\section{Intelligence Conversation Agents and Chatbots-Al / Virtual Assistant}

Intelligence conversational agents and Chatbot is an umbrella term, which is also known as chatterbots and virtual agents. Chatbots-Al and intelligence conversational agents are commonly used and are interchangeable; in this study, their functionalities are identical. Lester et al. (2004) as cited by Eeuwen (2017) have explained that the technologies behind their functionality to being natural language technologies are used to derive user engagement in text-based dialogues for information-seeking and task-oriented purposes across a wide range of applications. Eeuwen (2017) has further described chatbots or conversational agents as software applications capable of written or verbal human speech mimicry to stimulate communication or interaction with a real individual.

Similarly, chatbots-Al is a conversational agent developed to elicit intelligence conversation without a human presence, which aids in data retrieval for improved purchaser experience and enhanced consumer service. A more holistic definition by Kröger and Johansson, (2019) describes it as a computer program capable of eliciting human-like conversation in a text chat (e.g. Facebook Messenger, WeChat, WhatsApp, and more) or/and as voice assistant, which is a computer program capable of simulating human conversation verbally (e.g. Amazon's Alexa, Microsoft's Cortana, Apple's Siri, Google Voice Assistant, and more). Meanwhile, virtual assistant chatbots (VAC) supply information, services, and aid regarding web pages and implement various 
applications in the business, educational, governmental, healthcare (Laumer et al. 2019) and entertainment sectors. Accordingly, Osman (2019) has forecasted voice searches to consist of up to $50 \%$ of all searches and 21.4 million smart speakers utilizing the feature by 2020 . Additionally, the scholar has maintained that the voice commerce sales that yielded \$1.8 billion value in 2018 may potentially reach $\$ 40$ billion by 2022 .

Many technology firms supply the platforms capable of supporting chatbots-Al for consumer service, which include IBM Watson, Microsoft Bot Framework, and Google-owned DialogFlow. Furthermore, Walker's (2019) research on commercial chatbot eco-system has analyzed the chatbot plans of the "Big 4" technology firms, namely Microsoft, Google, Facebook, and Amazon. The author has claimed that when chatbots-Al and virtual assistants reach a certain level of smart, they can modify the manner in which people utilize technology, thereby rendering the existing practice as obsolete. Facebook Messenger is yet another of the most popularized messaging apps, trailing only after WhatsApp in monthly active users (Laudon \& Traver, 2017). Over a billion people currently utilize such messaging services and the numbers have continued to rise. The seamless advantages they offer to business owners cannot be overlooked due to the chatbots-Al integration capability. Facebook $\mathrm{M}$ is a virtual assistant within the Messenger app launched in 2015, which can perform a variety of tasks via text including making restaurant reservations, booking travel plans, and helping users to find birthday gifts. According to Facebook's trial with an Al assistant with additional human backup, it is perceived that user access to an exceptional assistant program will result in frequent utilization. Malaysian SME Corporation (2017) has reported that a larger percentage of Malaysian SMEs uses social media platforms (e.g. Facebook, WhatsApp, and Instagram), recording an average time of 2.58 hours daily on social media, 8.05 hours using the internet, and 4.02 hours using mobile internet to interact and engage with their consumers. According to Ismail (2017), $94 \%$ of Malaysian online population out of 19 million, according to the US census bureau, are using Facebook, while $59 \%$ use Twitter frequently. Chatbots-Al makes it easy, convenient, and faster for consumers to reach proprietors using the same messaging services they utilize daily.

The millennial generation as the increasing majority of purchasing power generally prefers chatbots-Al as their support channel (Osman 2019). He claims: "more than 60\% of customers prefer digital self-serve tools on websites and apps to answer their simple inquiries". As a result, chatbots-Al are becoming incredibly popular due to the fact that the time taken to interact with a real individual is too long when trying to call a company. Moreover, intelligence personal assistants and chatbots-Al may be able to understand what consumers are looking for despite being unsure of the manner in which to phrase such search or what one is even looking for (Laudon \& Traver 2017). If Al continues to improve and people learn to trust technologies such as chatbots, thus the importance of websites and native apps is likely to greatly diminish and results in a hit on a web search. While chatbots may not be a necessity for the near-term radar for many global firms, including Malaysian SMEs, any long-term strategic planning is recommended to account for voice and text conversation interfaces (Walker 2019).

Chatbots-AI is revolutionizing the way SMEs become connected with their consumers, specifically by allocating the ability for direct contact with a company via messaging apps, email, 
or text so as to nurture brand loyalty. Chatbot has impacted on every facet of the business environment, which includes: marketing (sales and operations), customer relationship management (CRM) (customer support), data analytics, predictive analytics for effective decision making (customer data collection and analysis) and organizational sustainable development (operational organisation). Furthermore, chatbots-Al in e-commerce provide better, faster, and improved services leading to consumer satisfaction and retention, as well providing insights for companies regarding consumers wishes and needs, which includes their purchasing process and context (Gentsch, 2019).

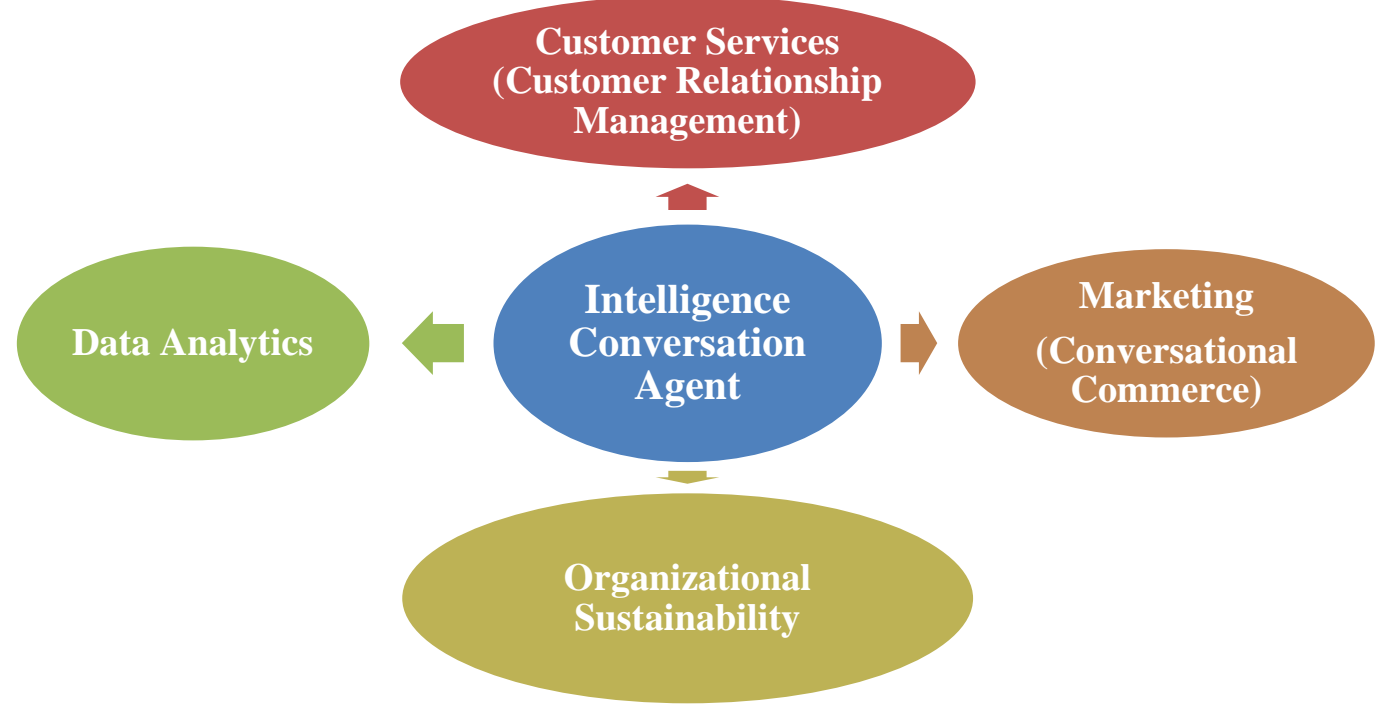

Figure 2: Concept Diagrams for Intelligent Conversation Agent and Chatbots and Its Application

Some of the functionalities of the intelligence conversational agent and chatbots-Al are explained as follows.

\section{Chatbots-Al for Data Analytics}

Chatbots-Al and its proper implementation can be used to facilitate, guide, and improve conversion rates. Their incorporation on company websites, social media platforms, and other landscapes renders it easier for users to effectively navigate such sites and customize the user experience. Generally, chatbots-Al can deliver 24/7, address users' questions and needs within seconds, and direct them to the right person(s) when they require assistance from the sales or support staff (Osman, 2019). Thus, they are an extremely effective tool for retrieving and emphasizing leads, guiding users to helpful resources, and personalizing user browsing experience via observing their decisions and activities for better service, as well as minimizing staff workload concomitantly by handling these tasks.

Big data analytics can be described as the process of analyzing a large amount of data so as to find hidden patterns and unknown correlations, which may correspond to market trends, consumer preferences, and other valuable information depending on the data origin. According to Reshmi and Balakrishnan (2018), the vast amount of data generated with digital tools has 
tremendously impacted on businesses to yield better strategic decisions, understand consumer needs, efficiently control process, and reduce cost. They have further claimed that chatbots-Al as a business intelligence tool has improved the analytical process capability, thereby leading to more effective use of information gained. This is applicable in various fields such as marketing, sales, customer service, and more for the purpose of improving operational efficiency and gaining competitive advantages and other benefits in business.

\section{Chatbots-Al for Marketing (Sales and Marketing Strategy) / Conversational Commerce}

IR4.0 through intelligent automation enables the optimization of consumer interaction, thereby offering a new market approach and consumer segmentation to individual preferences. Therefore, firms can manufacture an improved range of products due to the seamless and up-todate process for modifying consumer demands into tangible actions. The data expanding on the newest trends and consumer behavior transformation regarding consumer behaviors is achievable in real-time, rendering the production of novel products possible; this results in extensive business growth. Eeuwen (2017) has defined conversation commerce as the act of implementing chat, messaging, or other natural language interfaces for interactions with people, brands, or service. Chatbots previously have had no tangible role in the context of the bidirectional and asynchronous messaging, thus presenting opportunities for convenient, personalization, and decision-making processes assistance in the business. Moreover, the scholar Eeuwen (2017) has further described conversation commerce as the process of offering convenience via conversation in the natural language interface, whereby consumer may interact with firm representatives and chatbots-Al to obtain customer support, ask questions, tailored recommendations, attain reviews, and purchase products using the messaging apps themselves. In fact, chatbots-Al can help to improve sales, while marketing teams carry out tasks with ease and efficacy. For instance, GrowthBot is a sales and marketing chatbots-Al that allows interaction with professional on Facebook Messenger, Slack, SMS, and social media platforms. It can structure answers for common questions regarding people, brands, and technologies, and allows connectivity to tools such as HubSpot and Google Analytics in generating replies to web-traffic and other business-tailored questions (Accenture, 2017).

\section{Chatbots-Al for Customer Service / Customer Relationship Management (CRM)}

Chatbots emphasis upon various multi-step processes or input parameters to assist consumers faster as opposed to generating many questions. The Natural Language Processing (NLP) that is built within the program allows the chatbot to comprehend and facilitate a huge volume of consumer requests more efficiently. This is due to late responses and negative consumer service experiences that can compromise possible consumers from firms. Nguyen and Waring (2013) have claimed that $60 \%$ of US consumers have not proceeded for a purchase caused by subpar consumer service experience, which is estimated to be billions of dollars of lost sales among their retailers. Meanwhile, Garr and Jackson (2019) have highlighted that chatbot potential is increasingly valuable in businesses as prospective consumers and clients need not worry about the unavailability of sales and support team for over 24 hours every day of the week to respond 
to their queries. Besides, SMEs have no needs for hiring an additional workforce to maintain the live chat interface as the chatbots can be used instead to generate an automated response and guide the visitors towards the information required within seconds.

Newby et al. (2014) have defined customer relationship management (CRM) as the intuitive perspective towards generating an enhanced shareholder value via the establishment of the right relationships with core consumers and consumer segments. This is done by combining possible marketing strategies with information technology so as to generate profitable and long-term relationships with customers, as well as by utilizing data and information gathered to comprehend and co-create value with the consumers. The entire process entails a cross-functional implementation that encompasses processes, people, operations, and marketing capabilities; the approach is wholly incorporated via information, technology, and applications.

Chatbot-based customer support may potentially yield twice as fast response compared to voice-based support over the telephone at an even reduced cost (Accenture 2017). Apart from that, chatbots-Al can handle a high volume of requests and responses to frequently asked questions (FAQs), whereby the solutions are well-known and predictable; in contrast, the human agents assist the consumers with the more complex issues to reduce the time (Accenture, 2016; Nguyen, 2019). In China, WeChat allows the integration of Chatbot-Al, which gives room to the adoption of over 10 million users for using it in consumer service across various sectors (Accenture, 2016).

In the context of Malaysia, a considerable amount of organizations have adopted chatbots-AI technology for their business operation. AIA insurance chatbot-Al provides 24/7 online inquiries and insurance claim functionality, Air Asia (AVA) and Malaysia Airlines (MHChat) both are airliner chatbots-Al used for flight booking and consumer service; Celcom offers its virtual assistant Chatbot (Clive and Emma), Vitrox (ViTrox Al Chatbot) used for customer service, Shell Malaysia (Shelly) Ai-Powered Chatbot tool implemented for Lubricants Customers, and RHB Bank (Ringgit Plus) for automated self-loan processes, among others. The adoption of Chatbots$\mathrm{Al}$ is comparatively cost-effective compared to human-aided support; improves consumer satisfaction by reducing response time, increasing consumer convenience due to its availability at any time and location; and the increasing amount of first-time problem resolution. Thus, it positively impacts organizational brands by positioning them as an innovator, which helps in addressing new market segments and putting them ahead of their competitor; this is often referred to as a competitive advantage.

\section{Chatbots-Al for Organizational Sustainability}

Chatbots-Al can automate business operations for visible efficiency gains, which is undertaken for activity automation and streamlining, firm productivity improvements, and enhanced employee and consumer engagement. They are applicable virtually in every industry; in media, they are used to transmit news or sports results, while the tourism industry applies them for hotel and flight bookings, and as tourist guide services. Meanwhile, the banking and insurance sectors integrate Chatbots-Al to monitor accounts and transactions, consumer service, claim 
benefits, loans overall process, bills payment, and transfer execution. Similarly, healthcare implements the tool as a conversational agent for disease diagnosis, as well as health advisor and counsellor. In terms of education, they can serve as educational tools, whereas businesses with and/or without e-commerce ecosystem can use it for consumer service, digital marketing, selfservice online ordering process, as recommendation engines, and as enablers of conversational commerce (Laumer et al. 2019; Gentsch, 2018; 2019; Burgess, 2018; Yang \& Siau, 2018; Eeuwen, 2017)

Hence, the significance of a successful implementation of Chatbots-Al in the service sector, as well as the industrial manufacturing sector among Malaysian SMEs, will allow them to generate better performance and global sustainable competitive advantage. With regards to the chatbot technology acceptance research, few studies have been done across different industries, which encompass health, insurance, e-commerce application, banking, and more (Lucente, 2002; Offenbeek et al. 2013; Eeuwen, 2017; Laumer et al. 2019; Cardona et al. 2019). Although the levels of chatbot adoption support are similar across industries, the adoption gap between the intended and actual adoption among SMEs indicates the existence of an ambivalent systemdetermined or market-determined position (i.e. perceptions, attitudes and beliefs) to change the status quo (Offenbeek et al. 2013). This must be examined to fully comprehend the cost-benefit dynamics behind the implementation of chatbots in the context of business (Cardona et al. 2019).

\section{Overview of Technology Adoption Theories}

Adoption is the process where technology is chosen for utilization by a person or organisation. However, several frameworks and conceptual models have been incorporated to investigate the implementation of various technological innovations among SMEs in developed and developing countries alike. The researcher's interest when conducting research on technological innovation revolved around the factors under consideration, such as individual, organizational, technology, and environmental characteristics. These factors in either positive or negative way determine technologies adoption in e-commerce among SMEs. Some of the existing models are: Theory of Reasoned Action (TRA) by Ajzen and Fishbein (1980), Theory of Planned Behavior (TPB) by Ajzen (1991), Upper Echelon Theory (UET) by Hambrick and Mason (1984), Perceived e-readiness Model (PERM) by Molla and Licker (2005), Institutional Theory by Chatterjee et al. (2002) and Scott (2005), Technology Acceptance Model (TAM) as one of the most frequently researched model by Davis (1989), TAM2 by Venkatesh and Davis (2000), Technology-OrganizationEnvironment (T-O-E) by Tornatzky and Fleischer (1990), Diffusion of Innovation Theory (DIT) by Rogers (1995), Resource-Based View of the firm (RBV) by Barney et al. (2001), and Unified Theory of Acceptance and Use of Technology (UTAUT) by Venkatesh et al. (2003). Meanwhile, other relevant theories include the Stage Theory (Poon \& Swatman, 1999), Porter's models, the theory of organizational demography (Chuang et al. 2007), Task-Technology Fit-Model (TTF-Model) by Goodhue and Thompson (1995), Agency Theory, Dependency Theory, Motivation Model (MM) (Davis et al. 1992, Model of Personal Computing Utilization (MPCU) by Thompson et al. (1991), and Decision Maker-Technology-Organization-Environment Model (D-T-O-E) by Thong (1999). 
The widely adopted model for IT user acceptance and usage in varying domains is the Technology Adoption Model (TAM), which unveils the impacts of external variables such as perceived usefulness (PU) and perceived ease of use (PEOU) as the determinants for IT user's intention to use an innovation (Awa et al. 2015b). On the contrary, despite its validation and application, some of its backlashes include it is only very good when generating statistically reliable results, which can be improved further by adding additional components (Eeuwen, 2017). Other authors (Legris et al. 2003; Awa et al. 2012; Awa et al. 2015b) have also indicated for TAM integration with other models to capture variables of human and social change processes, and those capable of influencing innovation adoption process. However, the researcher recognized the TOE and DIT theories as prominently utilized for technology adoption at the organization or firm-level studies (Oliveira \& Martins, 2011; Abdullah et al. 2013). Furthermore, the TOE framework is in conformity with Diffusion of Innovation Theory (DIT) (Rogers, 1995). However, adoption predictors in terms of CEO and top management characteristics to changes; internal and external characteristics explanatory power of TOE makes it more viable (Awa et al. 2015b). The authors have thus claimed the framework concept to further develop IT adoption in SMEs so as to provide more exhaustive insight into the adoption phenomenon.

After a critical review of these theories, the UTAUT model, which is an extended outcome of the TAM and first established by Venkatesh et al. (2003) indicates that when allocated with novel technology, multiple factors will influence user decision to accept and use it (Chiemeke \& Evwiekpaefe, 2011). UTAUT is regarded as a very comprehensive theory because it has been established via an extensive review and incorporation of eight dominant theoretical models. They include: TRA, TAM, MM, TPB, a combination of TBP and TAM, MPCU, IDT, and Social Cognitive Theory (SCT). Hence, this renders UTUAL model a broad, robust and powerful model for technological innovation adoption studies.

\section{Unified Theory of Acceptance and Use of Technology (UTUAT)}

The UTUAT model is used to describe user intentions towards using innovation and the resulting usage behavior via four central constructs for user acceptance and usage behavior, which are performance expectancy, effort expectancy, social influence, and facilitating conditions (Venkatesh et al. 2003). Meanwhile, elements such as gender, age, experience, and voluntariness of use have been posited for the mediation the four constructs and their impact on usage intention and behavior (Venkatesh et al. 2003). Furthermore, the UTAUT model has been praised by Waehama et al. (2014) due to its capacity for explaining not less than $70 \%$ of technology acceptance behavior as opposed to other models, which can only describe not more than $40 \%$, as well as its function in establishing the acceptance of incoming novel technology. However, it has also faced criticism due to non-provision for conditions where expectation disconfirmation regarding core beliefs may happen, and thus potentially impacting behavioral intention and use (Venkatesh et al. 2012). Thus, incorporating the four predictors from UTUAT into T-O-E would enrich the applicability of both models to provide a better understanding of technology adoption compared to when their independent implementation. 
INTERNATIONAL JOURNAL OF ACADEMIC RESEARCH IN BUSINESS AND SOCIAL SCIENCES Vol. 9, No. 11, November, 2019, E-ISSN: 2222-6990 @ 2019 HRMARS

\section{Technology-Organization-Environment (T-O-E)}

The technology organization environment (TOE) framework is very unique and of importance, as it encompasses three contexts capable of influencing an organization towards adopting technological innovation (Abdullah et al. 2013; Tornatzky \& Fleischer, 1990; Puklavec et al. 2018). Research findings have shown that a successful implementation of any technology depends on different facets, namely technological characteristics, organizational characteristics, and external factors (Abdullah et al. 2013). The technology context describes the technological availability, whereby its characteristics are applicable within and outside of the enterprise. Then, the organizational context underlines enterprise characteristic, owner /top management support, organizational culture/mission and vision, quality of human resources, and sizes in terms of internal slack resources and specialization (Awa et al. 2015c; Chatzoglou \& Chatzoudes, 2016; Tornatzky \& Fleischer 1990; Puklavec et al. 2018). Finally, the environmental context is the determinant factors of the business operations territory, such as market structure, competitive pressure, business partner readiness, technology support infrastructure, and government regulation and support; they are among the significant facets impacting technology adoption (Awa et al. 2015a; Chatzoglou \& Chatzoudes, 2016; Tornatzky \& Fleischer, 1990; Puklavec et al. 2018). Regardless, TOE is deficient due to its failure to factor in the personalized attributes of SMEs and the significance of individual perspectives (Abdullah et al. 2013; Awa et al. 2015b).

\section{Integral Model of UTUAT Constructs and T-O-E Framework}

The intention to use any technology is anchored on the individual and/or organisation-level determination to accept first, and/or then systematically utilize such innovation for problemsolving purposes (Awa et al. 2017a). Theoretical scholars (e.g. TRA (Ajzen \& Fishbein, 1980); TPB (Ajzen 1991); UET (Hambrick \& Mason, 1984); PERM (Molla \& Licker, 2005); TAM (Davis, 1989); TAM2 (Venkatesh \& Davis, 2000); T-O-E (Tornatzky \& Fleischer, 1990); D-T-O-E (Thong, 1999); DIT (Rogers 1995), RBV (Barney et al. 2001; TTF (Goodhue \& Thompson 1995); UTAUT (Venkatesh et al. 2003) have developed respective technological frameworks describing and predicting technology adoption and its application for SMEs. They are in support of several research works in the information technology field that serve to investigate factors determining different technology implementation among SMEs. Such factors include e-business systems (Oliveira \& Martins, 2011; Mazzarol, 2015; Chatzoglou \& Chatzoudes, 2016), CRM (Newby et al. 2014; CruzJesus et al. 2019), e-commerce (Chiemeke \& Evwiekpaefe, 2011; Mazzarol, 2015; Awa et al. 2012; 2015a; Kurnia et al. 2015); enterprise systems (Awa et al. 2015a; 2017b); business intelligence system (Hatta et al. 2015; Popovič et al. 2019); Cloud Accounting System (Musa et al. 2016); eparticipation (Zolotov et al. 2018); digital marketing (Taiminen \& Karjaluoto, 2015); mobile banking (Oliveira et al., 2014; Baptista \& Oliveira 2015) conversational commerce (Kröger \& Johansson, 2019); and intelligence conversational agents and chatbot-Al (Eeuwen, 2017; Bredmar \& Jonsson, 2018; Laumer et al. 2019; Cardona et al. 2019). According to Awa et al. (2017), independent adoption of the TOE theoretical framework is insufficient, whereby its predictive and explanatory capabilities are augmented should individual contexts are integrated. Specifically, due to this idea, this research proposes a conceptual framework integrating the TOE 
and UTAUT frameworks, where the pertinent facets of UTAUT framework capture the different attributes of the adopter (Venkatesh et al. 2003; Awa et al. 2017). The proposed integrated framework shown in Figure 2 consists of two aforementioned technological innovation adoption models (i.e. UTAUT and TOE frameworks), which have been improved using fresh literary findings (Awa et al. 2017). Regardless, the combination of the TOE framework and UTUAT variables can enrich the applicability of technology adoption theories to the IS domain (Oliveira \& Martins, 2011; Awa et al. 2015, 2017; Maruping et al. 2017). Figure 2 integrates the UTUAT model constructs into the TOE framework and added two constructs namely; perceived cost (PC), perceived technology security constructs, to yield 11 total number of constructs. The framework positioned has incorporated relevant literary sources in delineating the individual adoption context in the perspective of social influences (e.g. Venkatesh \& Davis, 2000; Rogers, 2003).

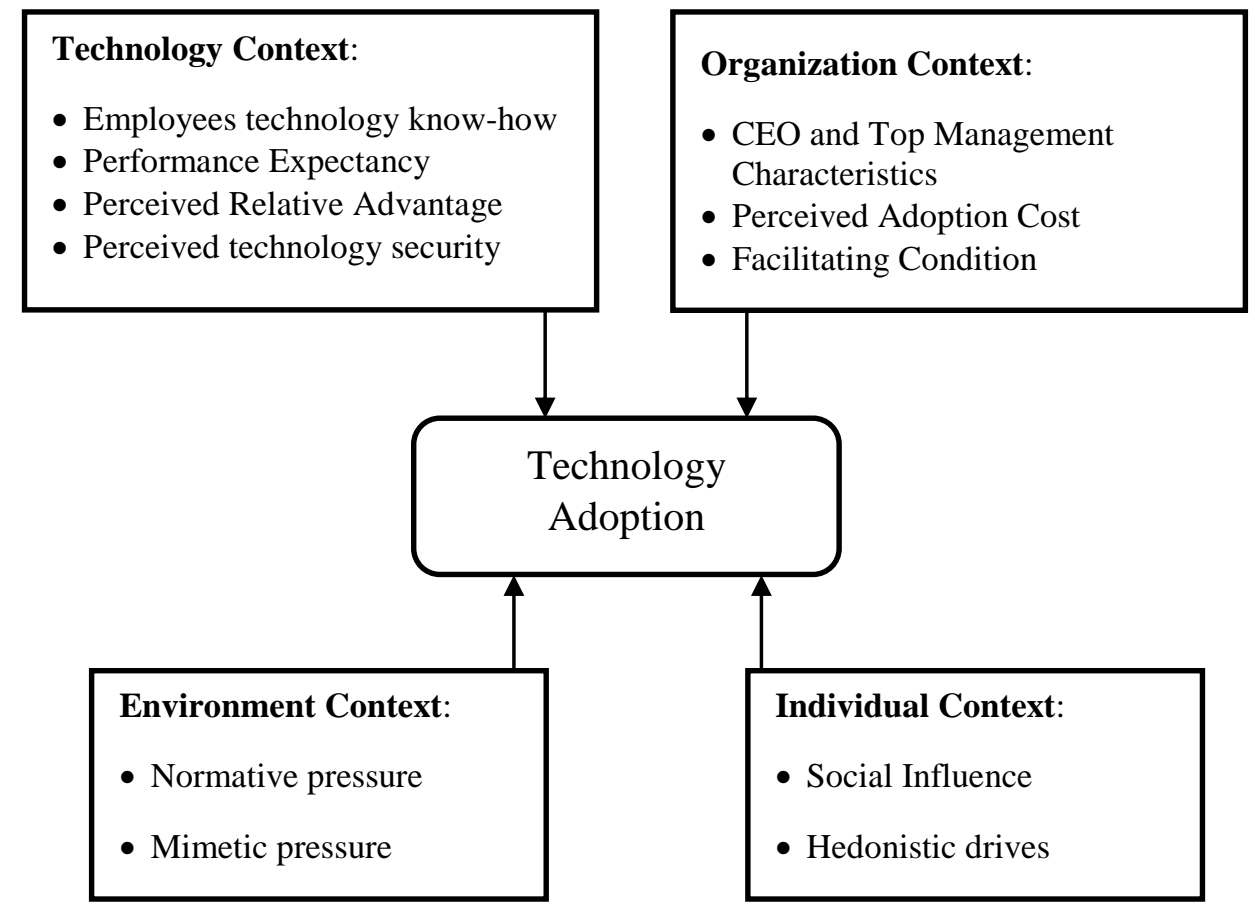

Figure 3: Proposed Conceptualized Framework for Intelligence Conversational Agent Technology Adoption Source: Awa et al. (2017)

The framework captures four drivers of adoption, whereby each is associated with a minimum of two to four factors resulting in their specificity. Rather than underestimate the power of interest shown by individual decision-makers as a determinant of the T-O-E framework, the proposed conceptual framework underlines that viewing decision-makers as a driver/context instead of a factor may potentially unleash key explanatory and predictive factors (Awa et al. 2017). The authors have maintained that accounting for individual manager attributes into the framework to serve as a context is theoretically proven by various scholars (e.g. Hambrick \& 
INTERNATIONAL JOURNAL OF ACADEMIC RESEARCH IN BUSINESS AND SOCIAL SCIENCES

Vol. 9, No. 11, November, 2019, E-ISSN: 2222-6990 @ 2019 HRMARS

Mason, 1984; Fillis et al. 2004; Riemenschneider \& McKinney, 2002; Venkatesh et al. 2003; Awa et al. 2015a; 2015b; Shiau et al. 2009; Thong, 1999; Grandon \& Pearson, 2004).

\section{Technology Context}

The context of technology is inclusive of all technologies deemed pertinent for the firm, encompassing those already utilized in the firm and those accessible in the market but not presently utilized (Baker, 2012). Similarly, it spans both the internal and external technologies available (Oliveira \& Martins, 2011). However, the proposed research framework captures the employee's technology know-how, perceived relative advantage, performance expectancy, perceived security, and privacy concern only.

\section{Employee's Technology Know-How}

In this study, employee's technology know-how is adopted in place of effort expectancy, which can be described as the extent of ease correlated with given technology utilization and thus impacts its intention for usage (Venkatesh et al. 2012). The researcher believes that the higher the technological innovation skills and knowledge of an employee, the more likely it is for them to use and/or adopt newer innovations in an organisation. It is imperative that newer technological innovations are not easy per se; instead, the level of employee(s) innovative skills will determine the manner in which an easy innovation can be perceived. Scholars (e.g. Oliveira et al. 2014; 2016; Baptista \& Oliveira, 2015) have undertaken investigations on mobile payment and mobile banking accordingly, whereby they have indicated effort expectancy to have no significance in explaining the behavioral intention to implement the technology. Furthermore, Abdullah et al. (2013) have claimed that technology is independently insufficient to enhance the efficacy and efficiency of SMEs in which their implementation should be complemented by a high level of technological staff competences. Similarly, Taiminen and Karjaluoto's (2015) study has revealed the lack of digitally innovative expertise among employees as a pertinent obstacle against digital channel adoption in SMEs.

\section{Performance Expectancy}

This term describes the extent to which an individual perceives the use of chatbot-Al will aid them in obtaining gains in job performance (Venkatesh et al. 2003). Venkatesh et al. (2012) have further explained PE as the extent to which the use of chatbots-Al technology will yield beneficial outcomes for the customers for undertaking specific activities. Meanwhile, Laumer et al. (2019) have underlined it as a crucial attribute for a user's acceptance of the chatbot technology in healthcare.

\section{Perceived Relative Advantage}

This term describes the extent to which the chatbot-Al is viewed as superior compared to the structure it substitutes (Rogers 1995). It refers to the expected advantages attainable by an organisation as a result of adopting chatbot-Al technology. Previous study findings (e.g. Thong 1999; Oliveira et al. 2014) have indicated the relative advantage of IT innovation to be amongst 
INTERNATIONAL JOURNAL OF ACADEMIC RESEARCH IN BUSINESS AND SOCIAL SCIENCES

Vol. 9, No. 11, November, 2019, E-ISSN: 2222-6990 @ 2019 HRMARS

the predictors repeatedly utilized in technological innovation adoption studies (Puklavec et al. 2018). Thong (1999) has further argued that a positive perception of the benefits offered by an IS may spur SMEs to implement the new technological innovation.

\section{Perceived Technology Security}

This term describes user perception of protection against potential damages and control of any personal data information submitted over the chatbot technology environment. Oliveira et al. (2016) have referred to PTS as perceiving security in undertaking financial transactions using mobile technologies. The authors have further maintained that in terms of technologies involving sensitive and personal data, their security capacity to guarantee secure transactions is important and is a direct determinant of consumer intention for technology implementation. With the advent of digitalization, Tofugear (2019), has underlined the opinion expressed by $56 \%$ of retailers in Asia that reveals protecting consumer data and privacy as a major challenge for their organizations.

\section{Organization Context}

The organizational context describes the attributes and resources possessed by a firm, which includes correlating structures between employees, intra-firm communication processes, firm size, firm scope, social influences, culture and structural configurations, organization mission and vision, information sources and communication channels, degree of centralization, perceived adoption cost, CEO and top management beliefs, facilitating conditions, complexity of market structure, and the amount of slack resources (Tornatzky \& Fleischer, 1990; Scupola 2009; Baker, 2012; Chatzoglou \& Chatzoudes, 2016; Eze et al. 2013; Awa et al. 2012). According to Puklavec et al. (2018), the CEO and top management of SMEs are the major decision-makers, thereby rendering the intention to use newer technological innovation to be anchored explicitly on them. Our framework examined CEO and top management, perceived adoption cost and facilitating condition under organizational context.

\section{CEO and Top Management Characteristics}

Various studies (e.g. Awa et al. 2017a; Puklavec et al. 2018; Chatzoglou \& Chatzoudes, 2016; Kurnia et al. 2015; Abdullah et al. 2013; Awa et al. 2017b) have found that CEO and top management characteristics serve as the major predictors of technological adoption in SMEs. These characteristics include: technology know-how, supportive climate, passion, leadership styles, academic qualification, and awareness of technology through networking. Therefore, the authors are in view of CEO and top management characteristics as an influential attribute in the three stages of the technological innovation adoption process. Chatzoglou and Chatzoudes (2016) have claimed that SME owners who are computer illiterate will be unable to perceive the benefits of IS, thus inhibiting their intention to use technological innovation. However, an innovative CEO and top management understand the relevance and significance of such technologies for their organisation and subsequently, undertake a prominent role in assuring other organizational team members for their acceptance for new innovation. Additionally, their 
commitment is very helpful across the organisation simply by providing the required technology infrastructure and sponsoring employees' training for technology usage. This will reduce employee resistance towards change within the organisation and ultimately increases the likelihood of full technological benefit materialisation (Kurnia et al. 2015).

\section{Perceived Adoption Cost}

Adoption cost and system maintenance are an undeniably pertinent attribute for SMEs as no organisation will display any interest in implementing e-commerce or ICT if the benefits do not exceed the losses (Alam et al. 2011). The author has claimed that Malaysian SMEs are typically critical of a system's development and maintenance costs due to budget constraints. Thong (1999) has revealed adoption cost as a significant adoption inhibitory factor, while Taiminen and Karjaluoto (2015) have confirmed financial resources/capital as a barrier towards SME growth in adopting and using the digital channel. Furthermore, Ghobakhloo et al. (2011) have argued the importance of a precise evaluation of their capabilities by SMEs so as to gain the advantages of IT adoption and prevent underestimation. They must be aware of IT's competency as a strategic instrument for their competing with fellow and larger rivals within the globalized market. Meanwhile, Puklavec et al. (2018) and Chatzoglou and Chatzoudes (2016) findings on business intelligence system and e-business adoption among SMEs, discover adoption cost to be insignificant. Chatzoglou and Chatzoudes (2016) have further claimed that those that have implemented e-business strategy proceed to do so without considering the initial adoption cost. Similarly, Puklavec et al. (2018) have posited cost-effectiveness as a non-representative of a substantial determinant; any excessive and high expectations during initial adoption process will not hinder future adoption and/or intention to use. In contrast, cost-effectiveness is understood as "when the benefits of adopting new technological innovation exceed the costs of such technology" (Popovic et al. 2018).

\section{Facilitating Condition (FC)}

The term describes the extent to which an SME believes in the presence of resources and support for the utilization of a specific technology whenever required (Venkatesh et al. 2003; 2012). According to Baptista and Oliveira (2015) SMEs who can voluntarily access a favorable set of facilitative conditions such as chatbot technology online tutorial, free training, demos, or support chat will show a greater intention to implement the innovation. In contrast, the creation of an enabling environment by the decision-maker who shows industrial leadership qualities in creativity, novelty, and collaborative learning such as hiring, developing, and rewarding innovative employees with a focus on achieving specific targets will ultimately facilitate the intention to use and/or adopt new innovation (Awa et al. 2012).

\section{Environment Context}

The environmental context is inclusive of the industrial structure, existence or lack of technology service providers, and regulatory environment, that is to say, an arena of organisation business environment with other industry, competitors, and dealings with government agencies (Baker 
2012; Oliveira \& Martins 2011). Baker (2012) has posited that organizations of any fast-growing industries have the tendency for innovation at a rapid pace. Therefore, the environmental context has been established as the strongest influence on the intention to use technological innovation due to the fact that it serves as a catalyst in the technology and organizational contexts of innovation adoption (Simões et al. 2019). However, Awa et al. (2017b) have established as per DiMaggio and Powell (1983) that the institutional theory constructs and normative and mimetic pressures summaries nearly all of the external factors highlighted by fellow researchers (Tornatzky \& Fleischer, 1990; Salwani et al. 2009; Awa et al. 2010).

\section{Normative Pressure}

Normative pressure is one of the results of requirements made by trading partners and customers, professional entities, legal frameworks, government and associated agencies, and the congress (Deephouse, 1996, as cited by Awa et al. 2017). Therefore, Puklavec et al. (2018) have asserted that the more external support is given to SMEs, the higher the SMEs' motivation for IT innovation adoption. This is due to their limited financial resources and the lack of experts in their respective organizations. In Chatzoglou and Chatzoudes' (2016) study among Greece SMEs, governmental support and consumer readiness, among others, are the most significant adoption drivers. Meanwhile, Abdullah et al. (2013) have looked into technology adoption among Malaysian SMEs and revealed that these firms receive different forms of assistance such as financial assistance, technology know-how, and free consultancy and training from governmental agencies. The authors have thus ascertained customer requirement and market trend as strong factors for technology adoption among Malaysian SMEs.

\section{Mimetic Pressure}

DiMaggio and Powell (1983) as cited by Awa et al. (2017) have posited that firms' response to mimetic pressures such as competitive pressure leads them towards streamlining their programs to suit conventional practices as shaped and/or initiated by the player(s). These findings are consistent with previous studies that underline SMEs' tendency to implement mindfulness and other relevant attributes of successful competitors, particularly those relating to innovation (DiMaggio \& Powell 1983; Awa et al. 2015b; Oliveira \& Martins, 2011).

\section{Individual Context}

Individual factors are a crucial determinant in new innovation adoption by SMEs. Various scholars (e.g. Awa et al. 2015a; 2015b) have emphasized that enterprise-level innovation adoption is largely dependent upon the functional and/or emotional feelings of the decision-makers. This is a reflection of their attitudes, perspectives, psychographics, and motivation, as well as other relevant individual factors. Furthermore, some research works have claimed that the characteristics of the owner-managers are the significant predictors in SMEs' technology adoption in Malaysia, such as academic qualification, commitment, passion, leadership style, technology know-how, and awareness of technological innovation trends (Abdullah et al. 2013). 
In the current study, individual factors were measured in the context of social influence and hedonistic drives.

\section{Social Influence}

Social influence is defined as the extent to which an individual view the importance of other people's belief that they utilize the new technology or adhere to surrounding expectations (Venkatesh et al. 2012). It is believed that individual behavior is impacted by the manner in which the opinions of peer groups or family members value the use of chatbot-Al technology. SMEs may perceive themselves as trendy, innovative, and professional due to adopting the new service technology, such as intelligence conversational agents. However, it has been reported that $73 \%$ of the executive class from the large cities of China had owned mobile phones as early as 1998 for the social status maintenance, rather than for traditional mobile usage (Awa et al. 2017). Besides, Ling and Yttri (2012) have suggested that the younger users of communication interfaces are more technologically-driven by socially influential elements, particularly during the stage of life where social development and learning occur.

\section{Hedonistic Drives}

Hedonistic drives are perceived as the pleasure and fun that is attained from the use of any specific technology (Venkatesh et al. 2012). Scholarly findings on innovation adoption have found it to be a significant adoption determinant, specifically in the areas of mobile technologies and social networking tools (Brown \& Venkatesh 2005; Balaid et al. 2014). Therefore, chatbots-Al utilization as a new business communication tool and enabler of conversational commerce should be enjoyed by SMEs, and subsequently result in its adoption.

\section{Conclusion}

The advent of a new digital industrial technology henceforth known as the fourth industrial revolution (Industry 4.0) has transformed the manner in which data are being gathered and analyzed across machines. This has enabled swift, dynamic, and effective processes to generate quality products and render services at a reduced price. The process connected machines, people, and physical assets into an integrated digital ecosystem, which results in seamless data generation, analysis, and communication; sometimes, it can take action based on such collected data itself without the need for human intervention. Such connection is powered by the advances in $\mathrm{Al}$, which is rapid technological development and evolving innovation fundamentally built upon machine learning and deep learning to give rise to the business intelligence tool otherwise known as intelligence conversational agents and Chatbots-Al. These technologies, however, enable richer insights to support real-time decision making and automation of business processes, thereby leading to business expansion into new markets, as well as increasing sales through big data and analytics. They have thus brought new dimensions to the business and industrial environment, resulting in a dramatic increase in industrial productivity, competitive advantage, and organizational sustainability. 
However, with regards to intelligence conversational agents and Chatbots-Al technology adoption and/or intention to use research in e-commerce among SMEs in developing countries such as Malaysia, such factor is relatively slowly building. This is attributable to the resources required, namely adoption costs and employees' technology know-how and relative advantage, which are otherwise known as the awareness of the strengths and benefits of chatbots-Al technology as perceived by SME CEO and managers. An in-depth review has revealed the environmental factors as the strongest motivating factor for SMEs to adopt and/or display their intent to use the new innovation due to the fact that it influences the technological and the contexts, whereas perceived trust in technology and data security are the major challenges for SMEs. Additionally, CEO and top management characteristics are the most significant determinant of SMEs to adopt and/or display the intent to use an innovation, which is found to be relevant in all three adoption stages. Theoretically, this research incorporates perceived technology security and UTUAT constructs into the T-O-E framework so as to shape an improved framework, which provides information into comprehending and forecasting technological adoption and/or the intention to use technology (e.g. intelligence conversational agents and chatbots-AI technology) among SMEs. However, integrating and/or combining other constructs with the T-O-E framework will inevitably enrich its applicability and facilitate and improve the explanatory and predictive facets of IS adoption. Additionally, the adoption factors and their constructs are intertwined between each construct in complementary, specifically by positioning some measure of difference for the weight of influence at one decision period versus any other. Therefore, this paper proposes an 11-factor theoretical framework across four adoption contexts to examine the intention to use intelligence conversational agent among Malaysian SMEs, whereby extended research will emphasize on the conceptualized framework's empirical validity and reliability.

\section{Theoretical and Contextual Contribution}

The research integral framework conceptually generated an in-depth theoretical and methodological discourse of the IT innovation adoption field, which could be differentiated from previous studies (e.g. Tornatzky and Fleischer, 1990; Venkatesh et al. 2007; Awa, Ukoha \& Igwe, 2017a; Awa, Ojiabo, \& Orokor, 2017b; Puklavec, Oliveira, \& Popovič, 2018). This study specifically positioned the components of perceived adoption cost and perceived technology security, which would ultimately serve as the originality contributed in the technology adoption literature, particularly in terms of intelligence conversational agents and Chatbots-Al technology. As a consequence, individual issues are viewed by this work as the contextual background in order to elicit the distinct attributes of the chatbots-Al technology adoption user as opposed to the T-O-E framework, which assesses separate attributes as a lone factor in the organizational context. Hence, the current work yields augmented conceptual robustness while also affording the exploratory platform for determining other IS adoption factors.

Furthermore, the findings obtained in this work offer impactful implications towards various stakeholders associated in the promotion of technological adoption. They include: 
academicians, SME CEOs and managers, technological service providers, and relevant governmental entities. Therefore, fellow researchers are encouraged to look into the conceptual research framework further and in detail with/out supplementary factors, for the purpose of other IT innovation adoptions, and in assessing the framework across varying climates (e.g. other countries and large organizations). Finally, future research may find it beneficial to inspect the TO-E factors as positioned by prior scholars (e.g. Thong 1999; Awa, Ukoha \& Igwe 2017a; Awa, Ojiabo, \& Orokor, 2017b) that have not been assessed in this work, as well as incorporating them with other well-known theories.

\section{References}

Abdullah, D. B., Abdullah, M. Y., \& Salleh, M. A. M. (2017). A review on the concept of fourth industrial revolution and the government's initiatives to promote it among youths in Malaysia. E-Bangi, Journal of Social Sciences and Humanities, 14(7), 1-8.

Abdullah, N. H., Wahab, E., \& Shamsuddin, A. (2013). Exploring the common technology adoption enablers among Malaysian SMEs: Qualitative findings. Journal of Management and Sustainability, 3(4), 78-91.

Abu, F., Jabar, J., \& Yunus, A. R. (2015). Modified of UTAUT theory in adoption of technology for Malaysia small medium enterprises (SMEs) in food industry. Australian Journal of Basic and Applied Sciences, 9(4), 104-109.

Accenture. (2016). Chatbots in customer service: Accenture interactive-Accenture digital, Dublin. Retrieved from https://www.accenture.com/t00010101t000000_w__brpt/_acnmedia/pdf-45/accenture-chatbots-customer-service.pdf

Accenture. (2017). Technology trends 2017. Retrieved on August 7, 2019, from https://www.accenture.com/_acnmedia/accenture/next-gen-4/tech-vision2017/pdf/accenture-tv17-full.pdf.

Ahmad, S. Z., Bakar, A. R. A., Faziharudean, T. M., \& Zaki, K. A. M. (2015). An empirical study of factors affecting e-commerce adoption among small-and medium-sized enterprises in a developing country: Evidence from Malaysia. Information Technology for Development, 21(4), 555-572.

Ajzen, I. (1991). The theory of planned behavior. Organizational Behavior and Human Decision Processes, 50(2), 179-211.

Ajzen, I., \& Fishbein, M. (1980). Understanding attitudes and predicting social behavior. Englewood Cliffs, NJ: Prentice-Hall.

Alam, S., Ali, M., \& Jani, M. (2011). An empirical study of factors affecting e-commerce adoption among SMEs in Malaysia. Journal of Business Economics and Management, 12(2), 375-399.

Ali, A. (2018). Virtual digital assistant usage: Statistics and trends [Electronic resource]. Retrieved from https://www.valuewalk.com/2018/12/virtual-digital-assistant-usage/. [in English].

Ameyaw, B., \& Modzi, S. K. (2016). Government policies, internationalization and ICT usage towards SME's growth: An empirical review of Ghana. Journal of Economics, Management and Trade, 1-11. 
Awa, H. O., Awara, N. F., \& Lebari, E. D. (2015c). Critical factors inhibiting electronic commerce (EC) adoption in Nigeria: A study of operators of SMEs. Journal of Science \& Technology Policy Management, 6(2), 143-164.

Awa, H. O., Baridam, D. M., \& Nwibere, B. M. (2015a). Demographic determinants of electronic commerce (EC) adoption by SMEs: A twist by location factors. Journal of Enterprise Information Management, 28(3), 326-345.

Awa, H. O., Ojiabo, O. U., \& Emecheta, B. C. (2015b). Integrating TAM, TPB and TOE frameworks and expanding their characteristic constructs for e-commerce adoption by SMEs. Journal of Science \& Technology Policy Management, 6(1), 76-94.

Awa, H. O., Ojiabo, O. U., \& Orokor, L. E. (2017b). Integrated technology-organizationenvironment (TOE) taxonomies for technology adoption. Journal of Enterprise Information Management, 30(6), 893-921.

Awa, H. O., Ukoha, O., \& Igwe, S. R. (2017a). Revisiting technology-organization-environment (TOE) theory for enriched applicability. The Bottom Line, 30(1), 2-22.

Awa, H., Nwibere, B., \& Inyang, B. (2010). The uptake of electronic commerce by SMEs: A meta theoretical framework expanding the determining constructs of TAM and TOE frameworks. Journal of Global Business and Technology, 6, 1-27.

Awa, H., Ukoha, O., \& Emecheta, B. (2012). Integrating TAM and TOE frameworks and expanding their characteristic constructs for ecommerce adoption by SMEs. Paper presented at the Proceedings of Informing Science \& IT Education Conference (InSITE).

Baker, J. (2012). The technology-organization-environment framework. In Information systems theory. New York, NY: Springer. 231-245.

Balaid, A., Rozan, M. A., \& Abdullah, S. (2014). Conceptual model for examining knowledge maps adoption in software development organizations. Asian Social Science, 10(15), 118-132.

Baptista, G., \& Oliveira, T. (2015). Understanding mobile banking: The unified theory of acceptance and use of technology combined with cultural moderators. Computers in Human Behavior, 50, 418-430.

Barney, J., Wright, M., \& Ketchen, D. J. (2001). The resource-based view of the firm: Ten years after 1991. Journal of Management, 27(6), 625-641.

Bredmar, J., \& Jonsson, S. (2018). Chatbot-Magic in a box? : A study of a chatbot in a Swedish bank. Uppsala University: Master's Thesis.

Brown, S. A., \& Venkatesh, V. (2005). Model of adoption of technology in households: A baseline model test and extension incorporating household life cycle. MIS Quarterly, 29(3).

Burgess, A. (2018). Al in action. In the executive guide to artificial intelligence. Cham: Palgrave Macmillan. 73-89.

Caletka, A. (2016). Capital efficiency meets Industry 4.0: The capital projects and infrastructure business case [Electronic resource]. Retrieved from https://www.pwc.com/us/en/industries/capital-projects-infrastructure/library/industry4-0-capital-efficiency.html

Cardona, D. R., Werth, O., Schönborn, S., \& Breitner, M. H. (2019). A mixed methods analysis of the adoption and diffusion of chatbot technology in the German insurance sector. 
INTERNATIONAL JOURNAL OF ACADEMIC RESEARCH IN BUSINESS AND SOCIAL SCIENCES

Vol. 9, No. 11, November, 2019, E-ISSN: 2222-6990 @ 2019 HRMARS

Proceedings of the 25th Americas Conference on Information Systems (AMCIS). Cancu, Mexico.

Chatterjee, D., Grewal, R., \& Sambamurthy, V. (2002). Shaping up for e-commerce: Institutional enablers of the organizational assimilation of web technologies. MIS Quarterly, 26(2), 6589.

Chatzoglou, P., \& Chatzoudes, D. (2016). Factors affecting e-business adoption in SMEs: An empirical research. Journal of Enterprise Information Management, 29(3), 327-358.

Chiemeke, S. C., \& Evwiekpaefe, A. E. (2011). A conceptual framework of a modified unified theory of acceptance and use of technology (UTAUT) model with Nigerian factors in ecommerce adoption. Educational Research, 2(12), 1719-1726.

Chuang, T. T., Rutherford, M. W., \& Lin, B. (2007). Owner/manager characteristics, organisational characteristics and IT adoption in small and medium enterprises. International Journal of Management and Enterprise Development, 4(6), 619-634.

Cruz-Jesus, F., Pinheiro, A., \& Oliveira, T. (2019). Understanding CRM adoption stages: Empirical analysis building on the TOE framework. Computers in Industry, 109, 1-13.

Davis, F. (1989). Perceived usefulness, perceived ease of use and acceptance of information technology. MIS Quarterly, 3(3), 319-340.

Davis, F. D., Bagozzi, R. P., \& Warshaw, P. R. (1992). Extrinsic and intrinsic motivation to use computers in the workplace. Journal of Applied Social Psychology, 22(14), 1111-1132.

Deephouse, D. (1996). Does isomorphism legitimate? Academy of Management Journal, 39(4), 1024-1039.

Department of Statistics Malaysia. (2018). Small and medium enterprises (SMEs) performance 2017. [Electronic resource]. Retrieved from https://www.dosm.gov.my/v1/index.php? $\mathrm{r}=$ column/cthemeByCat\&cat=159\&bul_id=cEI0bklpZHJaTIhRNDB3d2ozbnFIUT09\&menu_i $\mathrm{d}=$ TE5CRUZCblh4ZTZMODZIbmk2aWRRQT09

DiMaggio, P., \& Powell, W. (1983). The iron cage revisited: Institutional isomorphism and collective rationality in organizational fields. American Sociological Review, 48(2), 147-160.

Eeuwen, M. V. (2017). Mobile conversational commerce: Messenger chatbots as the next interface between businesses and consumers. University of Twente: Master's thesis.

Eze, S., Awa, H., Okoye, J., Emecheta, B., \& Anazodo, R. (2013). Determinant factors of information communication technology (ICT) adoption by government-owned universities in Nigeria: A qualitative approach. Journal of Enterprise Information Management, 26(4), 427-443.

Fillis, I., Johannson, U., \& Wagner, B. (2004). Factors impacting on e-business adoption and development in the smaller firm. International Journal of Entrepreneurial Behavior \& Research, 10(3), 178-191.

Garr, S. S., \&Jackson, C. (2019). Diversity \& inclusion technology: The rise of a transformative market. Technical report, RedThread Research.

Gentsch, P. (2018). Al in marketing, sales and service: How marketers without a data science degree can use Al, big data and bots. Springer. 
INTERNATIONAL JOURNAL OF ACADEMIC RESEARCH IN BUSINESS AND SOCIAL SCIENCES

Vol. 9, No. 11, November, 2019, E-ISSN: 2222-6990 @ 2019 HRMARS

Gentsch, P. (2019). Conversational Al: How (chat) bots will reshape the digital experience. In Al in marketing, sales and service. Cham: Palgrave Macmillan. 81-125.

Ghobakhloo, M., Arias-Aranda, D., \& Benitez-Amado, J. (2011). Adoption of e-commerce applications in SMEs. Industrial Management \& Data Systems, 111(8), 1238-1269.

Goodhue, D., \& Thompson, R. (1995). Task-technology fit and individual performance. MIS Quarterly, 19(2), 213-236.

Grandon, E. E., \& Pearson, J. M. (2004). Electronic commerce adoption: An empirical study of small and medium US businesses. Information \& Management, 42(1), 197-216.

Hambrick, D., \& Mason, P. (1984). Upper echelons: The organization as a reflection of its top managers. Academy of Management Review, 9(2), 193-205.

Hamid, N. A., Ibrahim, N. A., Ibrahim, N. A., Ariffin, N., Taharin, R., \& Jelani, F. A. (2019). Factors affecting tax compliance among Malaysian SMEs in e-commerce business. International Journal of Asian Social Science, 9(1), 74-85.

Hashim, H., \& Jumabhoy, A. (2017). Industry 4.0: SMEs are the Vanguards in catalysing change. [Electronic resource]. Retrieved from

http://www.smecorp.gov.my/images/article_KE/viewpoint.pdf

Hatta, N. N. M., Miskon, S., Ali, N. M., Abdullah, N. S., Ahmad, N., Hashim, H., Alias, R. A., \& Maarof, M. A. (2015). Business intelligence system adoption theories in SMES: A literature review. ARPN Journal of Engineering and Applied Sciences, 10(23), 18165-18174.

Idris, R. (2019). Industrial revolution 4.0: An overview of readiness and potential economic effects in Malaysia from millennial's perspective. World Scientific News, 118, 273-280.

Ismail, A. R. (2017). The influence of perceived social media marketing activities on brand loyalty: The mediation effect of brand and value consciousness. Asia Pacific Journal of Marketing and Logistics, 29(1), 129-144. doi: 10.1108/APJML-10-2015-0154

Ismail, A., Majid, A. H. A., Rahman, M. A., Jamaluddin, N. A., Susanty, A. I., \& Setiawati, C. I. (2018). Aligning Malaysian SMEs with the megatrends: The roles of HPWPs and employee creativity in enhancing Malaysian SME performance. Global Business Review. doi: 10.1177/0972150918811236.

Jayakrishnan, M., Mohamad, A. K., \& Abdullah, A. (2018). Digitalization approach through an enterprise architecture for Malaysia transportation industry. International Journal of Civil Engineering and Technology (IJCIET), 9(13), 834-839.

http://www.iaeme.com/IJCIET/issues.asp?JType=IJCIET\&VType=9\&IType=13

Jones, P., Packham, G., Beckinsale, M., Jahanshahi, A. A., Zhang, S. X., \& Brem, A. (2013). Ecommerce for SMEs: Empirical insights from three countries. Journal of Small Business and Enterprise Development.

Kaur, A., \& Sharma, P. C. (2018). Social sustainability in supply chain decisions: Indian manufacturers. Environment, Development and Sustainability, 20(4), 1707-1721.

Kotane, I., Znotina, D., \& Hushko, S. (2019). Assessment of trends in the application of digital marketing. Scientific Journal of Polonia University, 33(2), 28-35. 
Kröger, F. J., \& Johansson, F. (2019). Conversational commerce: A quantitative study on preferences towards Al-Fueled c-commerce platforms among digital natives in Sweden and Germany. Jonkoping University: Master's Thesis.

Kurnia, S., Choudrie, J., Mahbubur, R. M., \& Alzougool, B. (2015). E-commerce technology adoption: A Malaysian grocery SME retail sector study. Journal of Business Research, 68(9), 1906-1918.

Lahiri, R., Ding, J., \& Chinzara, Z. (2018). Technology adoption, adaptation and growth. Economic Modelling, 70, 469-483.

Laudon, K. C., \& Traver, C. G. (2017). E-commerce: Business. Technology. Society. $14^{\text {th }}$ ed. Boston: Pearson.

Laumer, S., Maier, C., \& Gubler, F. T. (2019). Chatbot acceptance in healthcare: Explaining user adoption of conversational agents for disease diagnosis. In Proceeding of the $27^{\text {th }}$ European Conference on Information System (ECIS). Stockholm \& Uppsala, Sweden.

Legris, P., Ingham, J., and Collerette, P., 2003. Why do people use information technology? A critical review of the technology acceptance model. Information \& management, 40(3), pp.191-204.

Lester, J., Branting, K., \& Mott, B. (2004). Conversational agents. The practical handbook of internet computing. Chapman \& Hall. ISBN-10: 9781584883814.

Ling, R., \& Yttri, B. (2002). Hyper-coordination via mobile phone in Norway. In J. Katz, \& M. Aakhus (Eds.). Perceptual contact. New York: Cambridge University Press.

Lucente, M. (2002). Conversational interfaces for e-commerce applications. Communications of the ACM, 43(9), 59-61.

Malaysian SME Corporation (2017). Industry 4.0 and its implications to SMEs. Retrieved on September 9, 2019, from

http://www.miti.gov.my/miti/resources/Industry4Point0/SMECorp_Industry_4_and_ Implications_to_SMEs.pdf

Markelova, P. (2017). The value of CRM in digital transformation in an organization case company: TPA global. Lahti University of Applied Sciences Ltd, Lahti: Bachelor's Thesis.

Maruping, L. M., Bala, H., Venkatesh, V., \& Brown, S. A. (2017). Going beyond intention: Integrating behavioral expectation into the unified theory of acceptance and use of technology. Journal of the Association for Information Science and Technology, 68(3), 623637.

Mazzarol, T. (2015). SMEs engagement with e-commerce, e-business and e-marketing. Small Enterprise Research, 22(1), 79-90.

Ministry of International Trade and Industry (MITI). (2018). National Industry 4.0: 12 Policy Framework. [Electronic resource]. Retrieved from https://grp.miti.gov.my/mitigrp/resources/Public\%20Consultation/Industry4.0FrameworkLayout_PublicReview(9Feb) V3_.pdf

Molla, A., \& Licker, P. (2005). E-commerce adoption in developing countries: A model and Instrument. Information \& Management, 42, 877 - 899. 
Musa, H., Li, S. C. H., Abas, Z. A., \& Mohamad, N. (2016). Adoption factor of mobile marketing: The case of small medium enterprises in Malaysia. International Review of Management and Marketing, 6(7S), 112-115.

Newby, M. H., Nguyen, T., \& Waring, T. (2014). Understanding customer relationship management technology adoption in small and medium-sized enterprises: An empirical study in the USA. Journal of Enterprise Information Management, 27(5), 541-560.

Nguyen, T. (2019). Potential effects of chatbot technology on customer support: A case study. Aalto University: Master's thesis.

Nguyen, T. H., \& Waring, T. S. (2013). The adoption of customer relationship management (CRM) technology in SMEs: An empirical study. Journal of Small Business and Enterprise Development, 20(4), 824-848.

OECD. (2019). OECD SME and entrepreneurship outlook 2019. Paris: OECD Publishing. Retrieved from https://doi.org/10.1787/34907e9c-en.

Oliveira, T., \& Martins, M. (2011). Literature review of information technology adoption models at firm level. The Electronic Journal Information Systems Evaluation, 14(1), 110-121.

Oliveira, T., Faria, M., Thomas, M. A., \& Popovič, A. (2014). Extending the understanding of mobile banking adoption: When UTAUT meets TTF and ITM. International Journal of Information Management, 34(5), 689-703.

Oliveira, T., Thomas, M., Baptista, G., \& Campos, F. (2016). Mobile payment: Understanding the determinants of customer adoption and intention to recommend the technology. Computers in Human Behavior, 61, 404-414.

Osman, M. (2019). Ecommerce statistics for 2019: Chatbots, voice, omni-channel marketing. [Electronic resource]. Retrieved from https://kinsta.com/blog/ecommercestatistics/\#.

Poon, S., \& Swatman, P. (1999). An exploratory study of small business internet commerce issues. Information and Management, 35(1), 9-18.

Popovič, A., Puklavec, B., \& Oliveira, T. (2019). Justifying business intelligence systems adoption in SMEs: Impact of systems use on firm performance. Industrial Management \& Data Systems, 119(1), 210-228.

Puklavec, B., Oliveira, T., \& Popovič, A. (2018). Understanding the determinants of business intelligence system adoption stages: An empirical study of SMEs. Industrial Management \& Data Systems, 118(1), 236-261.

Ramayah, T., Ling, N. S., Taghizadeh, S. K., \& Rahman, S. A. (2016). Factors influencing SMEs website continuance intention in Malaysia. Telematics and Informatics, 33(1), 150-164.

Reshmi, S., \& Balakrishnan, K. (2018). Empowering chatbots with business intelligence by big data integration. International Journal of Advanced Research in Computer Science, 9(1), 627-631.

Riemenschneider, C. K., \& McKinney, V. R. (2002). Assessing belief differences in small business adopters and non-adopters of web-based e-commerce. Journal of Computer Information Systems, 42(2), 101-107.

Rogers, E. (1995). Diffusion of innovation. New York, NY: Free Press.

Rogers, E. (2003). Diffusion of innovations. $4^{\text {th }}$ ed. New York, NY: The Free Press. 
Saleh, A. S., \& Burgess, L. (2009). Factors impacting the adoption and use of ICT in the Malaysian SME sector. 11th International Business Research Conference. Sydney, Australia: World Business Institute. 1-24.

Salwani, M., Marthandan, G., Norzaidi, M., \& Chong, S. (2009). E-commerce usage and business performance in the Malaysian tourism sector: Empirical analysis. Information Management \& Computer Security, 17, 166-185.

Scott, W. R. (2005). Institutional theory: Contributing to a theoretical research program. Great Minds in Management: The Process of Theory Development, 37, 460-484.

Scupola, A. (2009). SMEs' e-commerce adoption: Perspectives from Denmark and Australia. Journal of Enterprise Information Management, 22(1/2), 152-166.

Sennaar, K. (2019). Artificial intelligence in e-commerce: Comparing the top 5 largest firms. [Electronic resource]. Retrieved from https://emerj.com/ai-sector-overviews/artificialintelligence-in-ecommerce-amazon-alibaba-jd-com/

Shaharudin, M. R., Omar, M. W., Elias, S. J., Ismail, M., Ali, S. M., \& Fadzil, M. I. (2012). Determinants of electronic commerce adoption in Malaysian SMEs furniture industry. African Journal of Business Management, 6(10), 3648-3661.

Shiau, W., Hsu, P., \& Wang, J. (2009). Development of measures to assess the ERP adoption of small and medium enterprises. Journal of Enterprise Information Management, 22(1/2), 99118.

Simões, A., Oliveira, L., Rodrigues, J. C., Simas, O., Dalmarco, G., \& Barros, A. C. (2019). Environmental factors influencing the adoption of digitalization technologies in automotive supply chains. In 2019 IEEE International Conference on Engineering, Technology and Innovation (ICE/ITMC). pp. 1-7. IEEE.

SME Corp. Malaysia. (2018). Digitalisation survey of SMEs in 2018 [Electronic resource]. Retrieved from

http://www.smecorp.gov.my/images/SMEAR/SMEAR2017/ENG/Chapter2BoxArticle2.

Taiminen, H. M., \& Karjaluoto, H. (2015). The usage of digital marketing channels in SMEs. Journal of Small Business and Enterprise Development, 22(4), 633-651.

Tan, K. S., Chong, S. C., Lin, B., \& Eze, U. C. (2009). Internet-based ICT adoption: Evidence from Malaysian SMEs. Industrial Management \& Data Systems, 109(2), 224-244.

The Edge Markets. (2017). MITI: Malaysia's market too small for industry 4.0. Retrieved on 2 August 2019, https://www.theedgemarkets.com/article/miti-malaysias-market-too-smallindustry-40

Thompson, R. L., Higgins, C. A., \& Howell, J. M. (1991). Personal computing: Toward a conceptual model of utilization. MIS Quarterly, 15(1), 124-143.

Thong, J. (1999). An integrated model of information systems adoption in small businesses. Journal of Management Information Systems, 15(4), 27-31.

Tofugear. (2019). Asia digital transformation report. Tofugear, Hong Kong. Retrieved from https://www.tofugear.com/2019-asia-digital-transformation-report

Tornatzky, L., \& Fleischer, M. (1990). The process of technology innovation. Lexington, MA: Lexington Books. 
Ufford, L. (2017). Personalize the retail shopping experience with these 4 high-tech tools. Retrieved on August 2, 2019, from https://www.shopify.my/retail/how-more-retailers-arepersonalizing-the-shopping-experience-with-high-tech

Offenbeek, V. M., Boonstra, A., \& Seo, D. (2013). Towards integrating acceptance and resistance research: Evidence from a telecare case study. European Journal of Information Systems, 22(4), 434-454.

Venkatesh, V., \& Davis, F. D. (2000). A theoretical extension of the technology acceptance model: Four longitudinal field studies. Management Science, 46(2), 186-204.

Venkatesh, V., Morris, M., Davis, G., \& Davis, F. (2003). User acceptance of information technology: Towards a unified view. MIS Quarterly, 27(3), 425-478.

Venkatesh, V., Davis, F., \& Morris, M. G. (2007). Dead or alive? The development, trajectory and future of technology adoption research. Journal of the association for information systems, $8(4), 1$.

Venkatesh, V., Thong, J., \& Xu, X. (2012). Consumer acceptance and use of information technology: Extending the unified theory of acceptance and use of technology. Management Information Systems Quarterly, 36(1), 157-178.

Waehama, W., McGrath, M., Korthaus, A., \& Fong, M. (2014). ICT adoption and the UTAUT model. In Proceedings of the International Conference on Educational Technology with Information Technology. 7, 24-30.

Walker, J. (2019). Chatbot comparison: Facebook, Microsoft, Amazon, and Google. Retrieved on August, 2019, from https://emerj.com/ai-sector-overviews/chatbot-comparisonfacebook-microsoft-amazon-google/.

Yang, Y., \& Siau, K. L. (2018). A qualitative research on marketing and sales in the artificial intelligence age. MWAIS 2018 Proceedings.

Zolotov, M. N., Oliveira, T., \& Casteleyn, S. (2018). E-participation adoption models research in the last 17 years: A weight and meta-analytical review. Computers in Human Behavior, 81, 350-365. 